\title{
Hot Compression Behavior of Al-Zn-Mg Aluminium Alloy: Experiments and Simulations
}

\author{
C.Y. LI ${ }^{1, a}$, G.D. GAO ${ }^{1, b}$, X.P. ZHANG ${ }^{1, c,}$ \\ ${ }^{1}$ School of Materials Science and Engineering, Nanjing University of Science and Technology, \\ Nanjing 210094, P.R.China \\ a1067911365@qq.com, bgaoguoding90@gmail.com, c, xpzhang@njust.edu.cn \\ ${ }^{*}$ Corresponding author
}

Keywords: Al-Zn-Mg Aluminum Alloy, Hot Compression, Flow Stress, Finite Element Method.

\begin{abstract}
The hot deformation behavior of Al-Zn-Mg aluminum alloy was investigated by means of compression tests and Finite Element analysis method in the temperature and strain rate ranges of $350^{\circ} \mathrm{C}$ to $500^{\circ} \mathrm{C}$ and $0.1 \mathrm{~s}^{-1}$ to $0.4 \mathrm{~s}^{-1}$, respectively. The load-displacement data and the maximal cross section area $\mathrm{S}$ predicted by finite element method (FEM) were in good agreement with those from experiment. As expected, the flow stress was increased with strain rate, and decreased with deforming temperature. The flow stress of the Al-Zn-Mg aluminum alloy during hot compression deformation can be described by using Zener-Hollomon parameter, and it confirmed that the Zener-Hollomon parameters during hot deformation can be determined by simple compression testing in conjunction with validated numerical modeling. Finally, the relation of maximal cross section area $S$ of barreling profile and strain $\varepsilon$ during compression processing was established.
\end{abstract}

\section{Introduction}

Because of high strength, self-ageing, weldable, Al-Zn-Mg aluminum alloys have found a wide ranging application all over the world for fabrication of portable light weight military structures like bridges, shelters and missile containers, and the alloys are frequently formed by hot rolling or forging. In general, the hot rolling or forging is a complex and sometimes difficult process because tearing tends to occur at the surface of the hot rolling or forging. The behavior of the aluminum alloys in the hot forming process depends not only on their mechanical properties but also on the conditions under which extrusion deformation occurs, such as temperature, strain, strain rate and die geometry. Therefore, to ensure the quality of the hot deformation product, one needs first to understand the process in relation to the external process conditions and then to optimize the process [1].

Process simulation is a powerful tool to predict material behavior under specified deformation conditions. A reliable of the input data is a key to the reliability of the simulation results. The material data necessary for the simulation including a relationship among flow stress, strain, strain rate and temperature can be obtained from hot-working tests at a number of temperatures and strain rates for a consistent representation of deformation behavior [2].

The compression test is frequently used in evaluating the workability of materials, especially at elevated temperature. There are two inherent difficulties with the compression test that must be overcome by the test technique: buckling of the specimen and barreling of the specimen. Both conditions cause nonuniform stress and strain distribution in the specimen that makes it difficult to analyze the results. The best way to obtain the above-mentioned parameters is to conduct the hot working progress of $\mathrm{Al}-\mathrm{Zn}-\mathrm{Mg}$ aluminum alloy on the hot simulator and analyze the simulation results.

A Gleeble thermal simulator is a power tool to measure flow stress of metal at elevated temperature, but the charge is expensive. In this work, the hot deformation behavior of $\mathrm{Al}-\mathrm{Zn}-\mathrm{Mg}$ aluminum alloy was investigated by a universal test machine with a heat-furnace in the temperature and strain rate ranges of $350^{\circ} \mathrm{C}$ to $500^{\circ} \mathrm{C}$ and $0.1 \mathrm{~s}^{-1}$ to $0.4 \mathrm{~s}^{-1}$, respectively. And Finite Element analysis method was used to proofread the results. It confirmed that the Zener-Hollomon parameters 
during hot deformation can be determined by simple compression testing in conjunction with validated numerical modeling.

\section{Materials and experiments}

Pre-extruded Al-Zn-Mg aluminum alloy billets were used as the initial material in this study. Samples for compression tests were $15 \mathrm{~mm}$ in height and $10 \mathrm{~mm}$ in diameter. The compression tests were carried out on a universal test machine with a heat-furnace. Sample was kept at test temperature for $20 \mathrm{~min}$ to ensure good temperature uniformity and then compressed to a height of $6 \mathrm{~mm}$. The tests were preformed at $350^{\circ} \mathrm{C}, 400^{\circ} \mathrm{C}, 450^{\circ} \mathrm{C}$ and $500^{\circ} \mathrm{C}$ and strain rates of $0.1 \mathrm{~s}^{-1}, 0.2 \mathrm{~s}^{-1}$, $0.3 \mathrm{~s}^{-1}$ and $0.4 \mathrm{~s}^{-1}$.

FEA to simulate the hot compression process was performed using the above true stress-strain data, and modify the true stress-strain data based on the difference value of resulting FEA load-displacement data and that of experimental. FEA to simulate the hot compression process was performed using the modified true stress-strain data again, and recalculated the difference value of resulting FEA load-displacement data and the experimental data. Repeat the process till the entire match. Finite element simulation of the above hot compression has been performed using a commercial software package Deform-3D 6.1.

\section{Results and Discussion}

\section{Deformation of Al-Zn-Mg Aluminum Alloy during Hot Compression}

The typical equivalent strain distribution in compression sample was shown in Fig. 1. There was a barreling in the work because the friction between the compression specimen and the anvils that apply the load. The curves in Fig.1 showed the effect of strain rate and temperature on the deformation behavior of $\mathrm{Al}-\mathrm{Zn}-\mathrm{Mg}$ aluminum alloy, respectively. The flow stress initially increased with strain up to a peak (named the strain as $\varepsilon_{\mathrm{p}}$ ) and then decreased. The rates of strain hardening and strain softening varied with deformation temperature and strain rate. As was expected, the flow stress was increased with strain rate, and decreased with deforming temperature. Furthermore, the $\varepsilon_{\mathrm{p}}$ was 0.15 or under, and decreased as the strain rate decreased and the deformed temperature increased.

Fig. 2 shown the measured and the predicted by finite element method of maximal cross section area $S$ of barreling profile during compression processing, the predicted results by finite element method were in good agreement with those from experiment. It indicates that the friction coefficient used in the work is correctly. And the relation of $S$ and strain $\varepsilon$ can be fitted as following equation with a correlation coefficient of 0.993 :

$$
S=17.888 \mathrm{e}^{\frac{\varepsilon}{0.281}}+60.853
$$

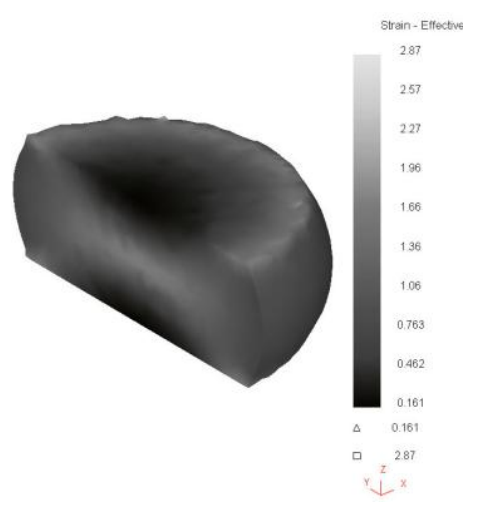

Fig.1 Equivalent strain distribution in compression sample at $60 \%$ compressive strain.

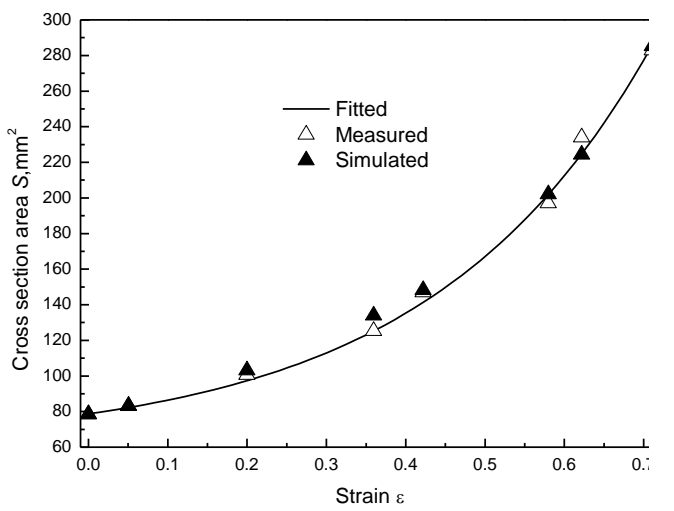

Fig. 2 Maximal cross section area $\mathrm{S}$ of barreling profile for $\mathrm{Al}-\mathrm{Zn}-\mathrm{Mg}$ aluminum alloy during compression processing 
Typical true stress-true strain curves calculated according to the inversed FEA method described above was presented in Fig.3.
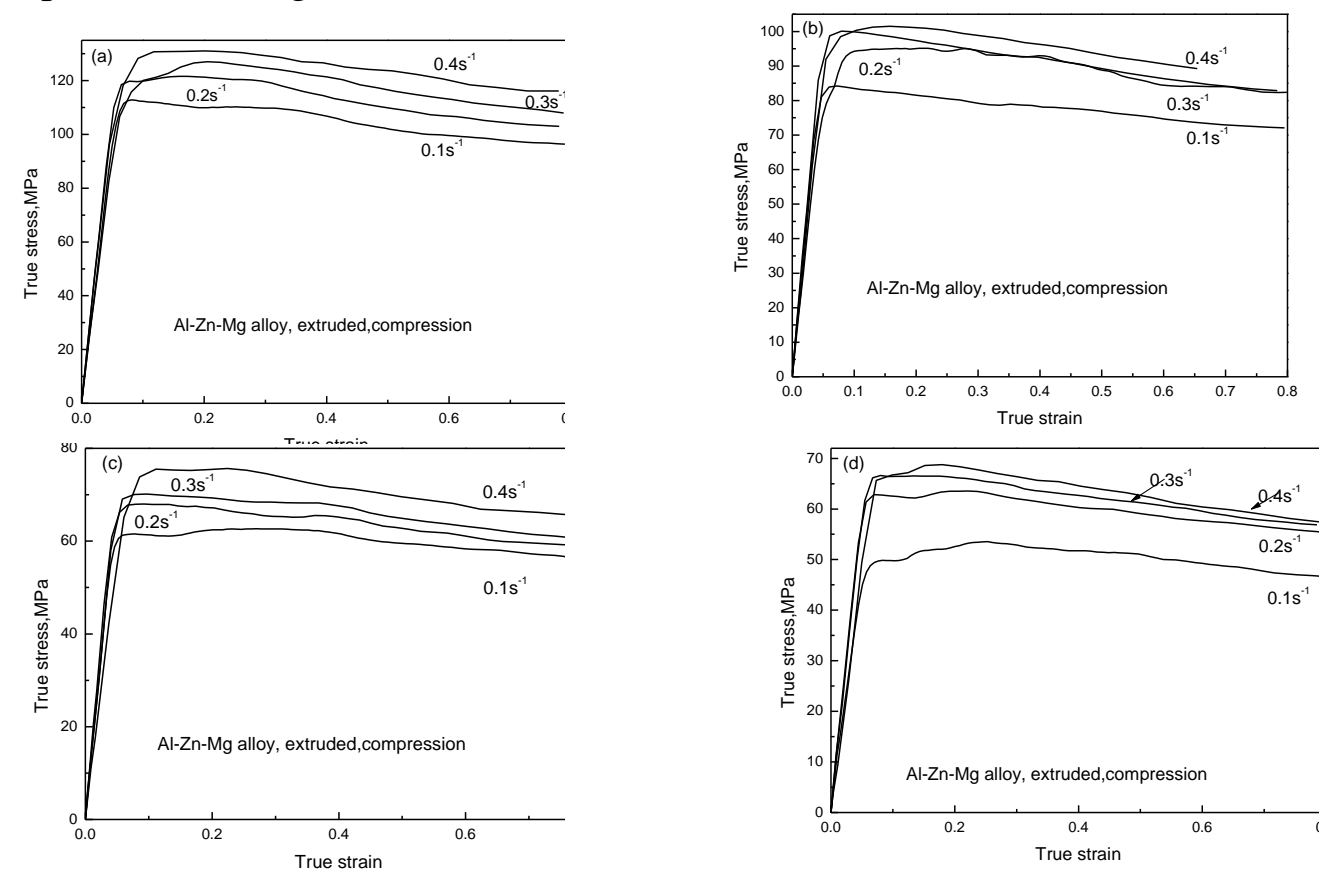

Fig.3 Effects of strain rate on the true strain-stress of Al-Zn-Mg aluminium alloy at (a) $350^{\circ} \mathrm{C}$, (b) $400^{\circ} \mathrm{C}$, (c) $450^{\circ} \mathrm{C}$ and (d) $500^{\circ} \mathrm{C}$

Fig.4 shown the displacement-load curves obtained from the hot compression experiments in comparison with the predicted results obtained from FEA. The responses obtained from simulation are in good agreement with experimental results. The matching scheme utilized here will be the optimization procedure to determine the constitutive behavior which provides the closest match with the experimental curve to the observed the inverse FEA load-displacement behavior.
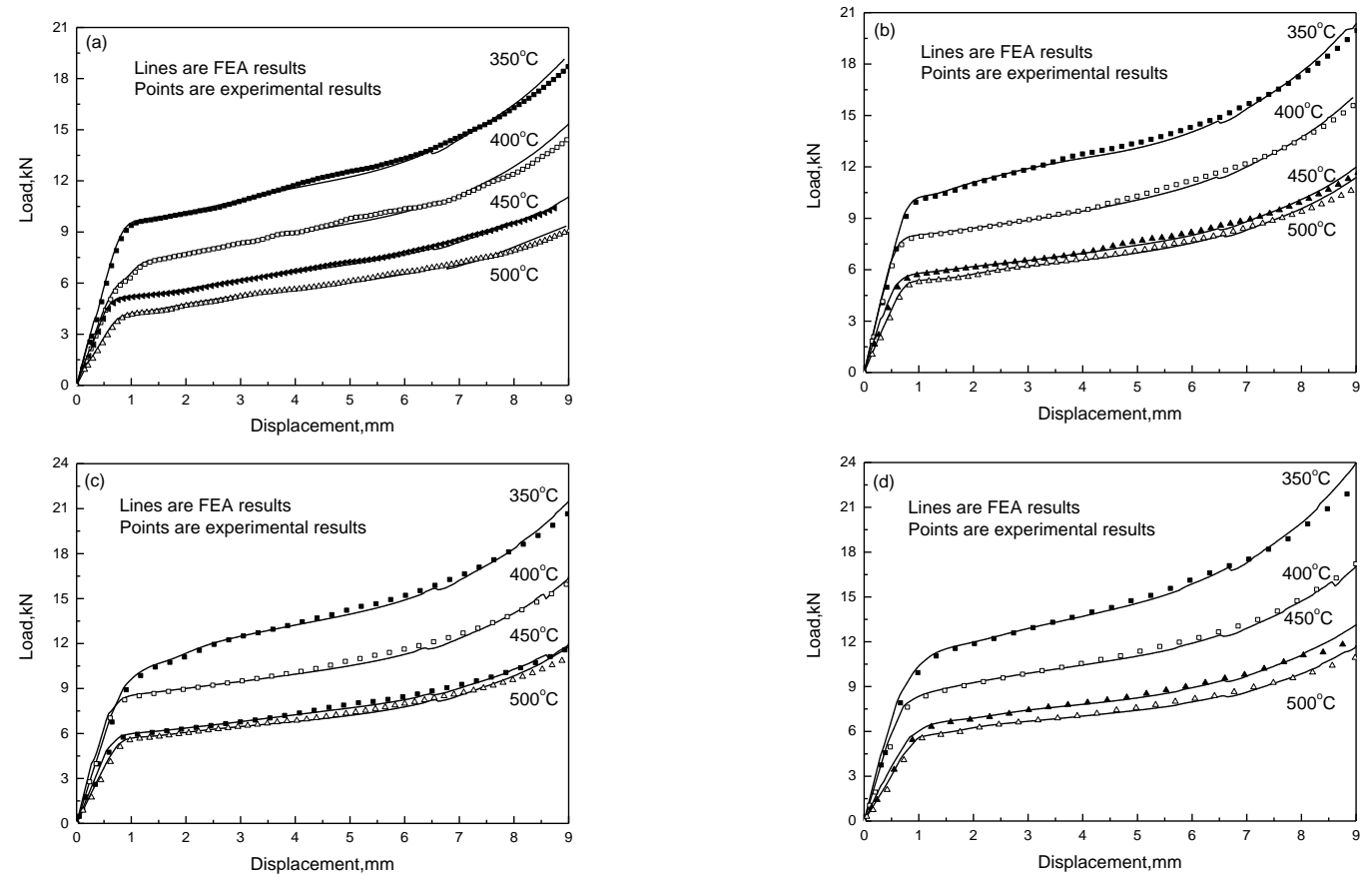

Fig.4 Comparison between displacement-load curves obtained by the inverse method and the experimental ones for samples with different temperature at (a) $0.1 \mathrm{~s}^{-1}$, (b) $0.2 \mathrm{~s}^{-1}$, (C) $0.3 \mathrm{~s}^{-1}$ and (d) $0.4 \mathrm{~s}^{-1}$ strain rate 


\section{Constitutive equations}

The constitutive analysis for the experimental alloy was presented in Fig. 5 and Fig. 6. The Arrhenius equation is widely used to describe the relation between the strain rate $\dot{\varepsilon}$, peak stress $\sigma_{\mathrm{p}}$ and absolute temperature $T$ at high temperature. It can also be shown with the Zener-Hollomon parameters as follows [1]:

$$
\begin{aligned}
& \dot{\varepsilon}=A\left[\sinh \left(\alpha \sigma_{\mathrm{p}}\right)\right]^{n} \exp \left(\frac{-Q}{R T}\right) \\
& Z=\dot{\varepsilon} \exp \left(\frac{Q}{R T}\right)=A_{3}\left[\sinh \left(\alpha \sigma_{\mathrm{p}}\right)\right]^{n}
\end{aligned}
$$

Where $n$ is the stress exponent, $\alpha$ is the adjustable stress multiplier, $Q$ is an activation energy for deformation, $R$ is the gas constant, $8.314 \mathrm{~J} / \mathrm{mol}$.
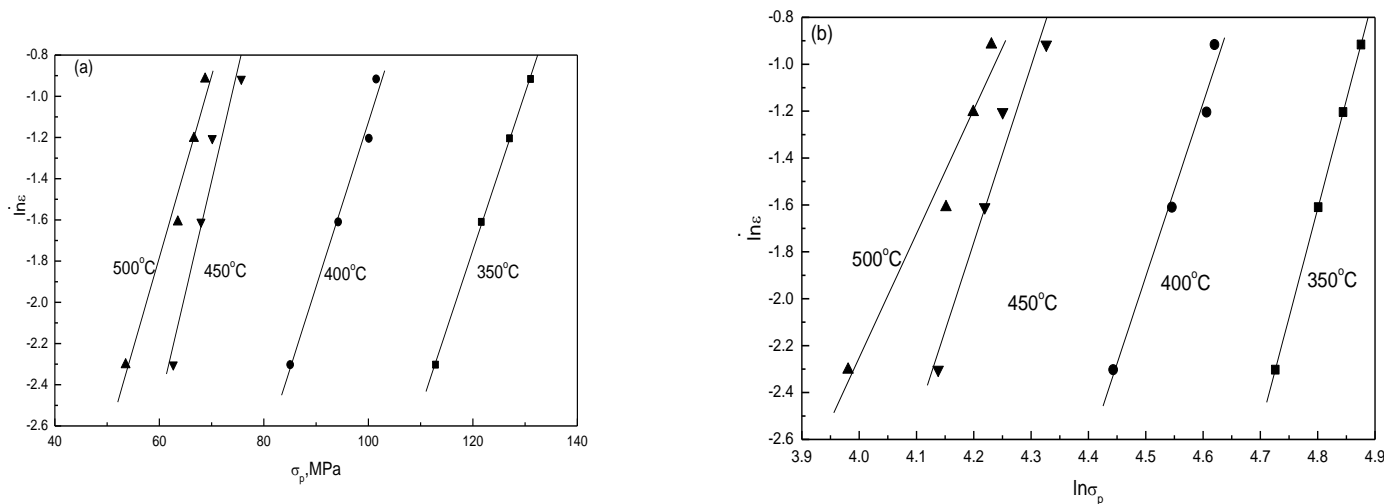

Fig. 5 Effect of the strain rate on the flow stress in (a) linear-log plot and (b) log-log plot
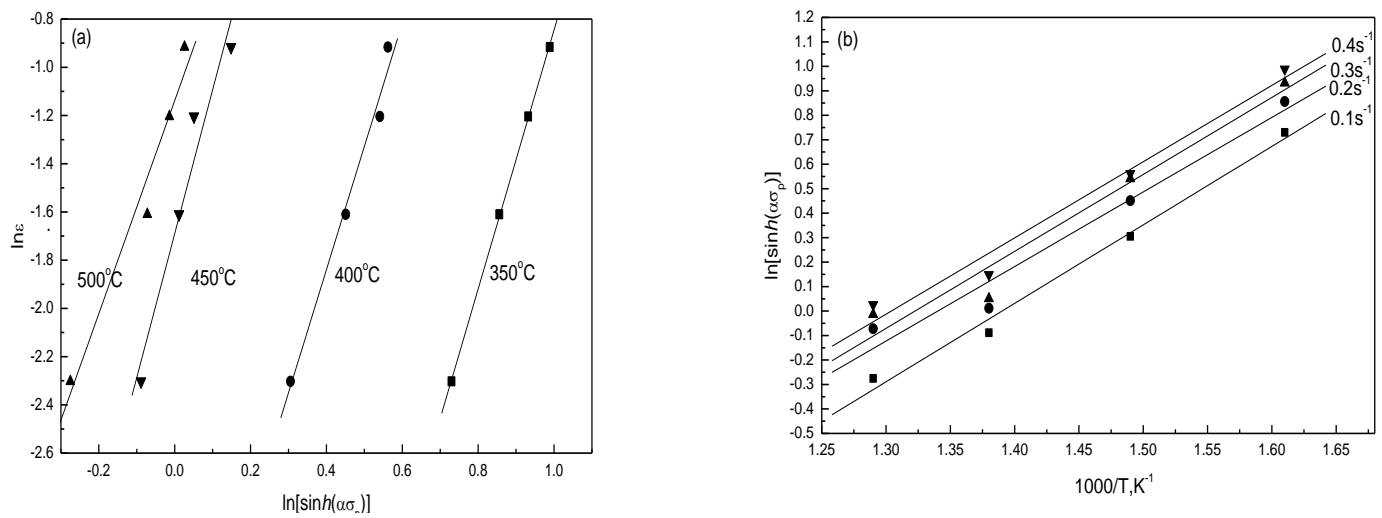

Fig. 6 Calculation of the activation energy Q of Al-Zn-Mg aluminium alloy during hot compression deformation. (a) The relation between peak stress and strain rate, (b) the relation between peak stress and deformation temperature

The constitutive analysis yields the value of activation energy for deformation $Q$, stress exponent $n$, adjustable stress multiplier $\alpha$ and material parameter $A_{3}$ of Eq.(2) and Eq.(3) were listed in Tab.1.

Tab. 1 Constants of constitutive analysis for $\mathrm{Al}-\mathrm{Zn}-\mathrm{Mg}$ aluminium alloy

\begin{tabular}{|l|l|l|l|l|l|}
\hline Constants & $\beta$ & $\mathrm{A}\left[\mathrm{MPa}^{-1}\right]$ & $\mathrm{n}$ & $\mathrm{Q}[\mathrm{kJ} / \mathrm{mol}]$ & $\mathrm{A}_{3}\left[\mathrm{~s}^{-1}\right]$ \\
\hline Value & 0.088 & 0.013 & 5.22 & 135.6 & $7.6 \times 10^{8}$ \\
\hline
\end{tabular}

The value of activation energy $Q, 135.6 \mathrm{~kJ} / \mathrm{mol}$, obtained for the present alloy was very slightly 
lower than that of $143-156 \mathrm{~kJ} / \mathrm{mol}$ for extrusion state 7075 alloy, ranged from $143 \mathrm{~kJ} / \mathrm{mol}$ to $156 \mathrm{~kJ} / \mathrm{mol}$, in the temperature range 300 to $400^{\circ} \mathrm{C}$ [4]. Because $Q$ for an alloy varies with the deformation temperature, thus there were some differences between the value of $Q$ of this work and that of the literature.

The plots of $\operatorname{lnZ}$ have been plotted versus $\log [\sinh (\alpha \sigma)]$ in Fig. 7. The plot brings all the tests data into a single line that summarizes the quality of the fit with a correlation coefficient of 0.99 and with a slope of 4.91 .

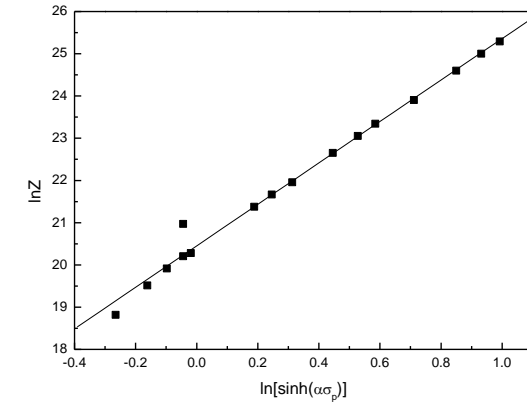

Fig.7 The relation of peak stress and $\mathrm{Z}$ of $\mathrm{Al}-\mathrm{Zn}-\mathrm{Mg}$ aluminum alloy

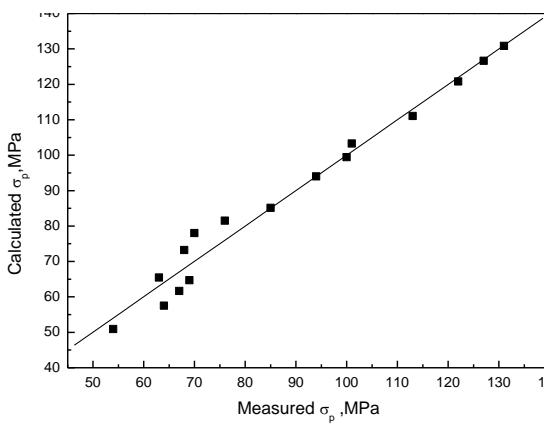

Fig.8. Comparison between measured and calculated stresses

To prove the parameters of the constitutive equation, the calculated flow stresses were plotted against the measured values in Fig. 8. The match is reasonably good and the mean error between the calculated and the measured values is less than $0.002 \%$ at $350^{\circ} \mathrm{C}$. However, at higher temperatures the error increased, so much that the deviation at $500^{\circ} \mathrm{C}$ reaches a larger $11.46 \%$. The phenomenon was also reported in AISI T1 high-speed steel [5], and the errors between the calculated and measured values at $950^{\circ} \mathrm{C}$ and $1150^{\circ} \mathrm{C}$ are $0.73 \%$ and $10.23 \%$, respectively. It is because that the activation energy $Q$ used in equation (2) is a same value for the experimental temperature range, but in fact $Q$ for an alloy varies with the deformation temperature. For example, the $Q$ of AISI T1 high-speed steel for the low temperature and the high temperature ranges are, respectively, 654 and $467 \mathrm{~kJ} / \mathrm{mol}$ in the true strain range of 0 to $0.6[5]$.

\section{Summary}

The hot deformation behaviour of $\mathrm{Al}-\mathrm{Zn}-\mathrm{Mg}$ aluminium alloy was investigated by compression test and Finite Element analysis method. Kinetic analysis of the flow stress variation with temperature and strain rate revealed that the rate equation is obeyed in the temperature range 350 to $500{ }^{0} \mathrm{C}$ and strain rate range $0.1 \mathrm{~s}^{-1}$ to $0.4 \mathrm{~s}^{-1}$. The flow stress increases with the increase of strain rate, and decreases with the increase of the deforming temperature. The flow stress of the $\mathrm{Al}-\mathrm{Zn}-\mathrm{Mg}$ aluminium alloy during hot compression deformation can be described by using Zener-Hollomon parameter including Arrhenius item, and the deformation activation energy is estimated to be $135.6 \mathrm{~kJ} / \mathrm{mol}$. It confirmed that the Zener-Hollomon parameters during hot deformation can be determined by simple compression testing in conjunction with validated numerical modeling.

The load-displacement data predicted by finite element method were in good agreement with those from experiment. The relation of maximal cross section area $S$ of barreling profile and strain $\varepsilon$ during hot compression can be fitted as $S=17.888 \mathrm{e}^{\frac{\varepsilon}{0.281}}+60.853$.

\section{Acknowledgement}

This work was supported by Jiangsu Qinglan Project; the Scientific Research Foundation for the Returned Overseas Chinese Scholars, State Education Ministry; the Fundamental Research Funds for the Central Universities, No. 30920140112008; Key Graduation Project of Nanjing University of Science and Technology. 


\section{References}

[1] R. Bobbili, B.Ramakrishna, V. Madhu, A.K. Gogia: Def. Technol. Vol. 11(2015), p93-98.

[2] F.A. Slooff, J. Zhou, J. Duszczyk : Scripta Mater. Vol. 57(2007), p759-762.

[3] S. Ma, Y. Liu, X.H. Dong, X.P. Zhang: J. Wuhan Univ. Technol.-Mater. Sci. Ed. Vol. 28 (2013), p172-177.

[4] R.Y. Lapovok, M.R. Barnett, C.H.J. Davies: J. Mater. Process. Technol., Vol. 146(2004), p408-414.

[5] J.T. Liu, H.B. Chang, R.H. Wu: Mater. Charact. Vol. 45 (2000), p175-186. 